\title{
Simple, rapid, and accurate malaria diagnostic platform using microfluidic-based immunoassay of Plasmodium falciparum lactate dehydrogenase
}

\author{
Wang Sik Lee ${ }^{1,2}$, Taejoon Kang ${ }^{3}$, Kyung Jin Kwak' ${ }^{1}$ Kyoungsook Park ${ }^{4}$, So Yeon Yi ${ }^{5,6}$, Ui Jin Lee ${ }^{5,6}$, \\ Yong Beom Shin $2,3,5$ and Jinyoung Jeong ${ }^{1,2^{*}}$
}

\begin{abstract}
This work reports on a rapid diagnostic platform for the detection of Plasmodium falciparum lactate dehydrogenase $(P f D H)$, a representative malaria biomarker, using a microfluidic microplate-based immunoassay. In this study, the microfluidic microplate made it possible to diagnose PfLDH with a small volume of sample (only $5 \mu \mathrm{L}$ ) and short time (<90 min) compared to conventional immunoassays such as enzyme-linked immunosorbent assay (ELISA). Moreover, the diagnostic performance of PfLDH showed high sensitivity, specificity, and selectivity (i.e., $0.025 \mathrm{pg} / \mu \mathrm{L}$ in phosphate-buffered saline and $1 \mathrm{pg} / \mu \mathrm{L}$ in human serum). The microfluidic-based microplate sensing platform has the potential to adapt simple, rapid, and accurate diagnoses to the practical detection of malaria.
\end{abstract}

Keywords: Microfluidic microplate, Immunoassay, Malaria, PfLDH, Diagnosis

\section{Introduction}

Malaria is a serious infectious disease that is transmitted from mosquitoes to humans causing 219 million infections and 435,000 deaths worldwide in 2017 according to the World Health Organization (WHO) [1, 2]. Despite vast efforts to reduce the risk of malaria, it still has high mortality and morbidity due to inaccurate diagnosis and increased drug resistance [3]. Malaria infection is caused by Plasmodium parasites that are transmitted by the bite of Anopheles spp. mosquitoes such as Plasmodium falciparum (P. falciparum) and Plasmodium vivax (P. vivax) [1]. In particular, P. falciparum is an important target of malaria diagnosis because it accounts for $90 \%$ of worldwide malaria mortality [4]. P. falciparum has various biomarkers including lactate dehydrogenase (LDH),

\footnotetext{
*Correspondence: jyjeong@kribb.re.kr

${ }^{1}$ Environmental Disease Research Center, Korea Research Institute of Bioscience and Biotechnology (KRIBB), 125 Gwahak-ro, Yuseong-gu, Daejeon 34141, Republic of Korea

Full list of author information is available at the end of the article
}

histidine rich protein2 (HRP2), aldolase, and hypoxanthine phosphoribosyl transferase [5]. Conventional diagnosis of $P$. falciparum is mainly dependent on HRP2 detection by immunoassay [6]. However, HRP2 deletion mutants have been reported in several countries [7-12]. Therefore, it is necessary to develop an alternative diagnostic biomarker instead of HRP2. In this study, we chose $P$. falciparum lactate dehydrogenase $(P f \mathrm{LDH})$ as an alternative biomarker for the diagnosis of malaria (P. falciparum), which is a water-soluble enzyme that converts pyruvate to lactate in glycolysis in $P$. falciparum infection $[5,13,14]$.

Conventional malaria diagnosis methods include a microscopic examination and antibody-based rapid diagnostic tests (RDTs) [5, 15-19]. Although the microscopic examination is the gold standard for malaria diagnosis and is rapid and cost-effective, it requires highly trained personnel. Meanwhile, the RDT, a lateral flow immunoassay, is a useful method in low-resource environments because it is possible to provide cost-effective, 
rapid ( $<30 \mathrm{~min}$ ) and simple detection methods using the nitrocellulose strip $[5,20]$. However, RDTs have sensitivity limitations, such as the inability to detect $<200$ parasites $/ \mu \mathrm{L}$ or $<1 \mathrm{ng} / \mathrm{mL}[16,19,21,22]$. To overcome the limitations of existing diagnostics, several studies demonstrated improved detection efficiency by introducing nanoparticles such as magnetic beads. Markwalter et al. successfully detected PfLDH up to $21.1 \pm 0.4$ parasites/ $\mathrm{mL}$ within $45 \mathrm{~min}$ using antibody-immobilized magnetic beads as a colorimetric assay [14]. Additionally, they developed a simultaneous capture and sequential detection of two malarial biomarkers (PfLDH and HRP2) on magnetic microparticles [23]. Kim et al. detected HRP2 up to $0.1 \mathrm{ng} / \mathrm{mL}$ using antibody-immobilized magnetic beads and quantum dots using an automated dropletbased microfluidic device [20]. Although these studies were developed to overcome the limitations of conventional enzyme-linked immunosorbent assay (ELISA), nanoparticle-based immunoassays still require a relatively complex surface functionalization process and a large amount of antibody to immobilize the antibody.

To overcome these limitations of conventional ELISAbased diagnosis and to improve the diagnosis of PfLDH, we present a microfluidic microplate-based immunoassay. This microfluidic microplate is an Optimiser ${ }^{\mathrm{TM}}$ microplate, which is one of the next-generation immunoassay platforms, and the existing 96-well plate was developed in the form of a microfluidic channel [24-26]. In this study, we demonstrated that the microfluidic microplate-based immunoassay provides an ultrafast, simple, and precise immunoassay for PfLDH diagnosis. The microfluidic microplate-based immunoassay significantly reduced the amount of reagents $(5 \mu \mathrm{L})$ and diagnosis time (<90 min) compared to conventional ELISA, as well as enabling high-sensitivity diagnostics $(0.025 \mathrm{pg} / \mu \mathrm{L})$. Additionally, we confirmed that PfLDH in human serum can be diagnosed up to $1 \mathrm{pg} / \mu \mathrm{L}$. Based on the results of our study, we expect that the microfluidic microplate-based immunoassay platform will be widely used for infectious disease diagnosis as well as in malaria.

\section{Results and discussion}

\subsection{Microfluidic microplate-based immunoassay for PfLDH} diagnosis

Figure 1a illustrates the construction of a microfluidic microplate and the procedure for detecting $P f L D H$. The whole body of this microplate consisted of a conventional 96-well plate with an inlet for pipette injection, an outlet that is open toward the absorbent pad, and a microfluidic channel between them. The microfluidic microplate is a spiral microfluidic channel and has a 1.5-fold larger surface area and a 50-fold surface-area-to-volume ratio than conventional ELISA plates [24]. The microfluidic microplate is operated by capillary action between the microchannel and adsorbent pad. The process is passive flow regulation, which can lead to accurate and rapid immunoassay results. This flow system involves the sequential addition of reagents, such as antibodies and antigens, to the microfluidic channel (Fig. 1b). The diagnostic procedure in the microfluidic channel is similar to that of conventional ELISA. In general, conventional ELISA was used to target the absorbance signal from the $3,3^{\prime}, 5,5^{\prime}$-tetramethylbenzidine (TMB) substrate; however, the microfluidic microplate-based immunoassay used the chemiluminescence signal from the 10-acetyl3,7-dihydroxyphenoxazine (ADHP)-based chemiluminescent substrate due to the microfluidic channel structural properties. ADHP is not normally a fluorescent molecule; instead, it is converted to a fluorescent form (resorufin) in the presence of horseradish peroxidase (HRP) and hydroxide peroxide [27]. Consequently, microfluidic microplates have the advantage of using a highly accessible microfluidic surface, capillary design, and highly sensitive substrate compared to ELISA. Therefore, the volume required to diagnose the targets can be significantly reduced, and the overall diagnosis time can be much faster than that of conventional ELISA (Fig. 1c). This immunoassay platform shows that it is appropriate to diagnose PfLDH with a small amount of antibody and fast diagnosis time.

\subsection{Performance of the microfluidic microplate for PfLDH immunoassay}

To optimize the microfluidic microplate-based immunoassay for PfLDH, we selected an antibody pair through a sandwich ELISA (data not shown). Based on the results of the ELISA, monoclonal mouse PfLDH antibody was selected as the capture antibody (Cap- $\mathrm{Ab}$ ), and polyclonal rabbit $P f \mathrm{LDH}$ antibody was selected as the primary antibody (1st-Ab). In this condition, we confirmed that $P f \mathrm{LDH}$ was diagnosed up to $0.1 \mathrm{pg} / \mu \mathrm{L}(10 \mathrm{pg}$ in $100 \mu \mathrm{L}$ ) by ELISA (Fig. 2). To use selected antibody pairs in the microfluidic microplate, the optimization of Cap$\mathrm{Ab}$ adsorption was significantly important to the whole immunoassay process. We compared the diagnosis efficiency in carbonate-bicarbonate buffer (pH 9.6, Fig. 3a) and phosphate-buffered saline (PBS, $\mathrm{pH}$ 7.4, Fig. 3b) to optimize $\mathrm{Cap}-\mathrm{Ab}$ adsorption. In general, carbonatebicarbonate buffer was used as a coating buffer in ELISA because the high $\mathrm{pH}$ was attributed to the better dissolution of proteins into the buffer and improved adsorption to the positive charged plate. However, $\mathrm{Cap}-\mathrm{Ab}$ in PBS showed better diagnosis efficiency than Cap-Ab in carbonate-bicarbonate buffer (Fig. 3). This indicates that PBS (pH 7.4) was appropriate substance to adsorb Cap$\mathrm{Ab}$ on the microfluidic microplate wall. 
a
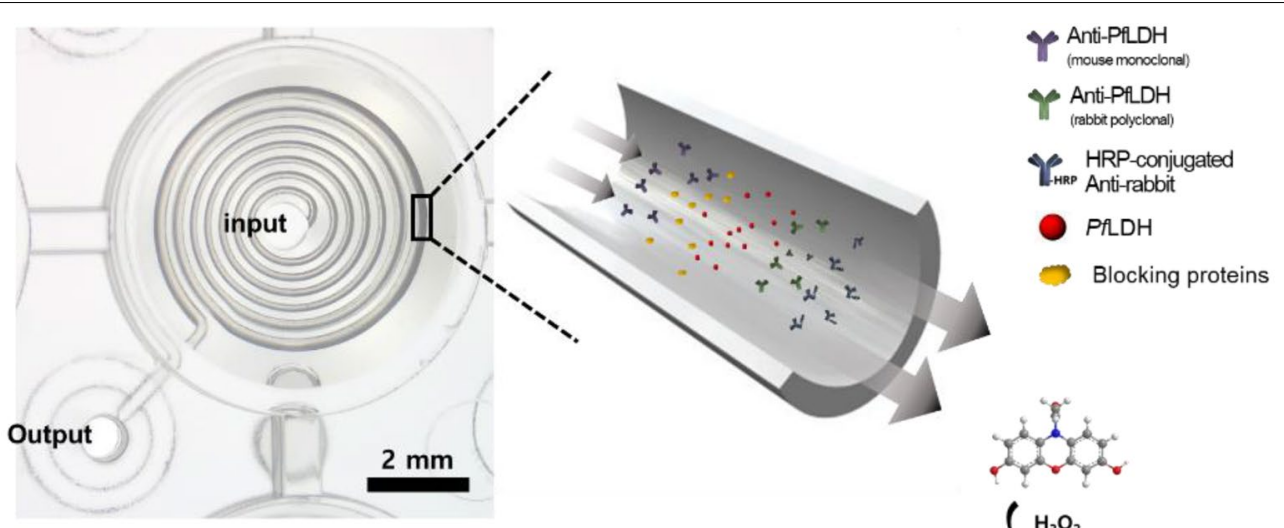

b

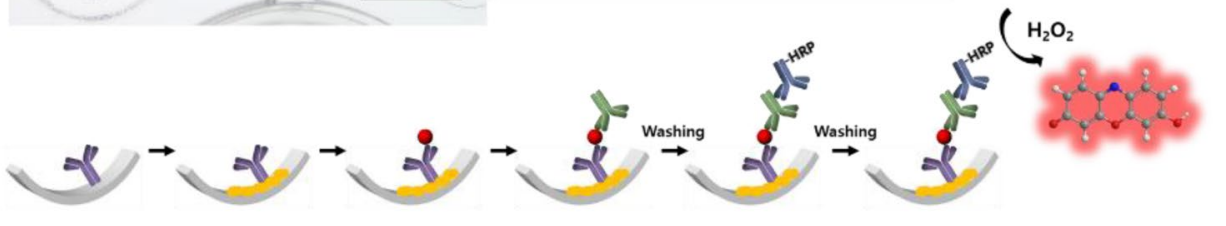

C

\section{Conventional ELISA}
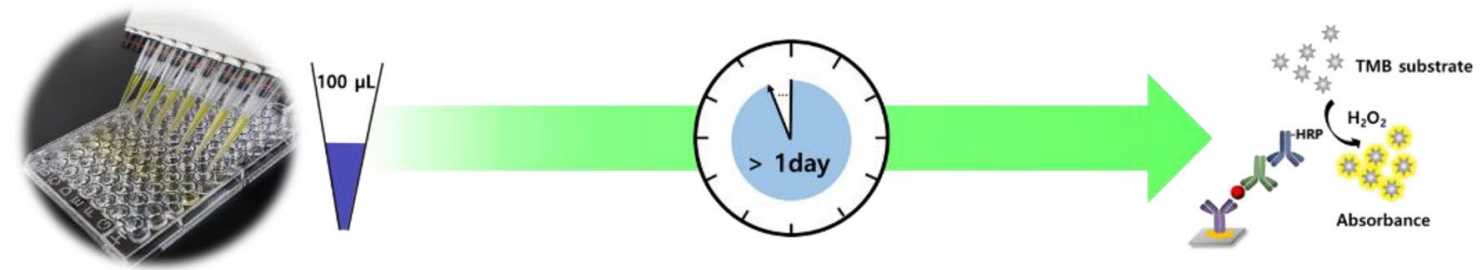

Microfluidic microplate
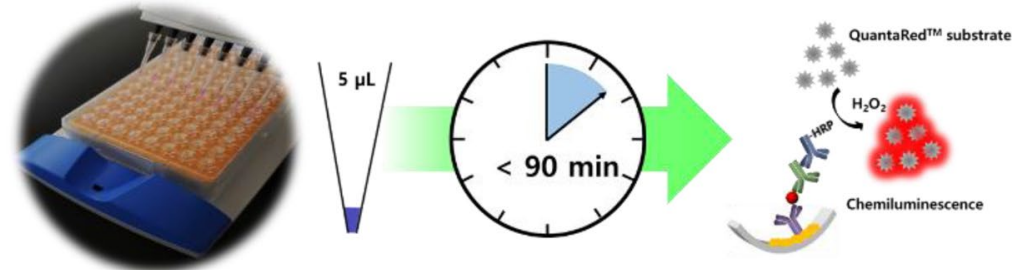

Fig. 1 Schematic illustration for diagnosis of PfLDH using microfluidic microplate. a Optical image of the microfluidic microplate. The microfluidic microplate allows for low volume and rapid immunoassay due to microfluidic channel. b Flow sequence for detection of PfLDH. c Comparison of PfLDH detection method using conventional ELISA and microfluidic microplate

To evaluate the PfLDH diagnostics capability in the microfluidic microplate, we diagnosed PfLDH in the range from 0.05 to $500 \mathrm{pg}$, including the negative control (PfLDH 0 pg). As shown in Fig. 4, PfLDH showed a limit of detection (LOD) of $0.025 \mathrm{pg} / \mu \mathrm{L}(0.125 \mathrm{pg}$ in $5 \mu \mathrm{L})$, and the diagnosis of $P f \mathrm{LDH}$ was visually confirmed through the chemiluminescence image. The LOD was calculated as the minimum detectable signal $\left(\mathrm{FL}_{P f \mathrm{LDH}=0}+3 \mathrm{SD}_{P-}\right.$ $f \mathrm{LDH}=0)$. Additionally, we compared PfLDH with Plasmodium vivax lactate dehydrogenase $(P v \mathrm{LDH})$ and $\mathrm{BSA}$ for selectivity and specificity at concentrations of $0,0.5$, 5, 50, and $500 \mathrm{pg} / 5 \mu \mathrm{L}$. As shown in Fig. 5, this platform showed high selectivity and specificity for PfLDH. Based on the results of experiments, it was clearly shown that PfLDH can be ultrafast and precise in our sensing platform.

To confirm its applicability in clinical diagnosis, we performed the diagnosis of $P f \mathrm{LDH}$ in human serum. $P f \mathrm{LDH}, P v \mathrm{LDH}$, and BSA were prepared in commercial human serum at concentrations of $0,0.5,5,50$, and $500 \mathrm{pg} / 5 \mu \mathrm{L}$. Figure $6 \mathrm{a}$ shows the diagnosis results of the PfLDH in human serum using ELISA. The results show that the non-specific binding is high, even in the absence of $P f \mathrm{LDH}$. It means that $P f \mathrm{LDH}$ in human serum 


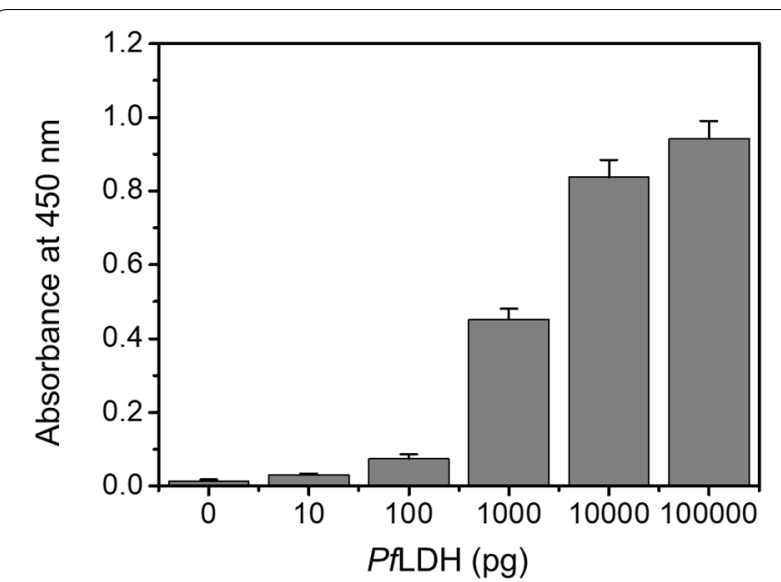

Fig. 2 Diagnosis of PfLDH using the ELISA. The optical density were measured at $450 \mathrm{~nm}$ wavelength with 0 to $100 \mathrm{ng} / 100 \mu \mathrm{L}(\mathrm{n}=3)$

can be detected by ELISA but is not suitable for highly sensitive diagnosis due to its high non-specific binding. In general, one of the drawbacks of ELISA is the falsepositive result due to non-specific binding in the presence of various proteins, such as human serum, it must be improved for application in clinical diagnosis [28]. In contrast to the ELISA results, Fig. $6 \mathrm{~b}$ shows that PfLDH in human serum can be diagnosed up to $1 \mathrm{pg} / \mu \mathrm{L}$ (5 pg in $5 \mu \mathrm{L}$ ) with high selectivity and specificity using microfluidic microplate. This LOD is an ideal sensitivity at which to adapt the clinical application because PfLDH-infected patients typically show PfLDH plasma levels of approximately 3-15 pg/ $\mu \mathrm{L}[13,29]$. Recently, Tonigold et al. demonstrated that the conditions of antibody adsorption (i.e., $\mathrm{pH}$ and isoelectric point of antibody) were significantly affected by the orientation of the antibody [30]. They validated that adsorbed antibodies on the polystyrene (PS) beads showed superior targeting properties compared with covalently coupled antibodies with the PS beads. The microfluidic microplate is also composed of PS; therefore, the Cap-Ab, which is well oriented on the microfluidic channel, led to the high sensing capability of PfLDH, including PfLDH spiked in human serum. Additionally, the large surface area and capillary forces of the microfluidic channel also contributed to the sensing performance. Based on the results of PfLDH diagnosis in human serum, we expect that our immunoassay platform can be widely used for the clinical diagnosis of infectious diseases such as malaria.

\subsection{Diagnostics capability of the microfluidic microplate-based immunoassay}

Table 1 summarizes and compares recent studies on the diagnosis of PfLDH. Recently, many studies have developed high-sensitivity, high-selectivity, and cost-effective diagnostics based on aptamers or nanoparticles [3135]. Nanoparticles, such as novel-metal nanoparticles and magnetic nanoparticles, are applied for lateral flow immunoassay or combined with aptamers to improved diagnostic performance. However, these sensors require the complicated surface functionalization and stabilization of nanoparticles or require a relatively large amount of sample volume. On the other hand, the microfluidic microplate-based immunoassay improved the conventional 96-well plate to a microfluidic channel, significantly reducing the time and amount of reagents required
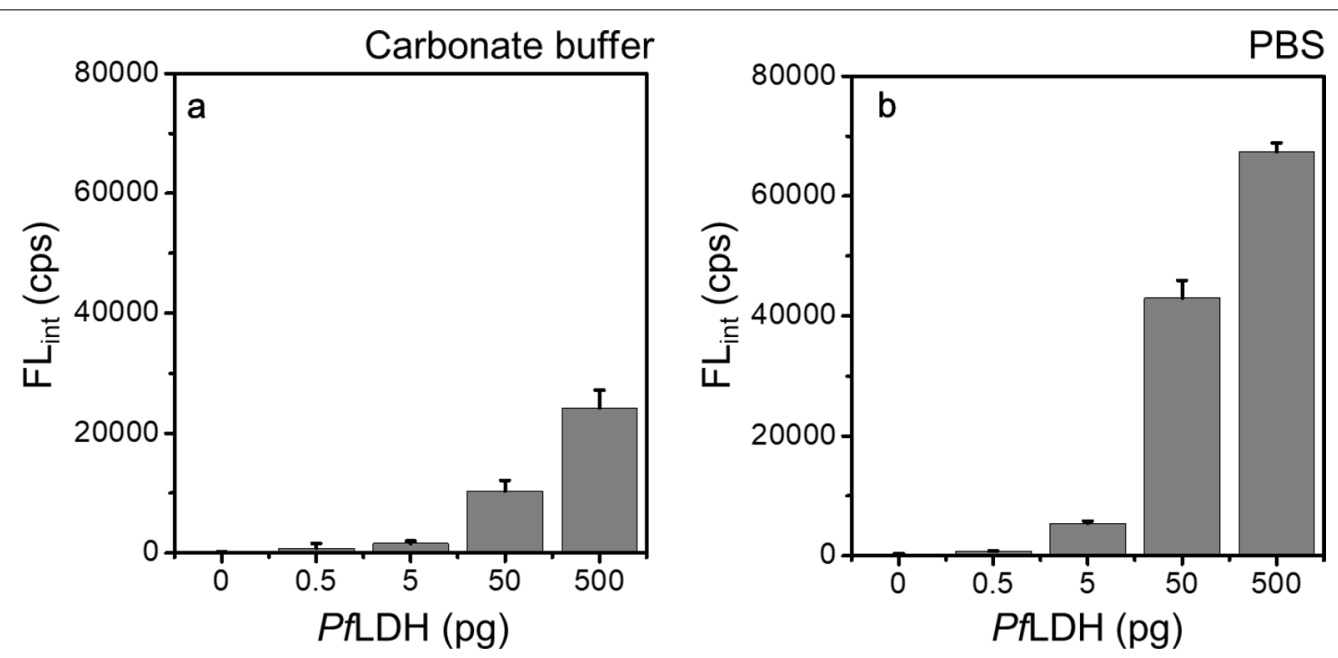

Fig. 3 Optimization of the Cap-Ab adsorption. The Cap-Ab coating efficiency was compared two coating buffers. To detect the PfLH in the microfluidic microplate, the Cap-Ab was prepared in a carbonate-bicarbonate buffer ( $\mathrm{pH}$ 9.6) and $\mathbf{b}$ PBS (pH 7.4). The chemiluminescence were measured by BioTek multimode reader (Excitation: $530 \mathrm{~nm}$, Emission: $590 \mathrm{~nm}, \mathrm{n}=3$ ) 


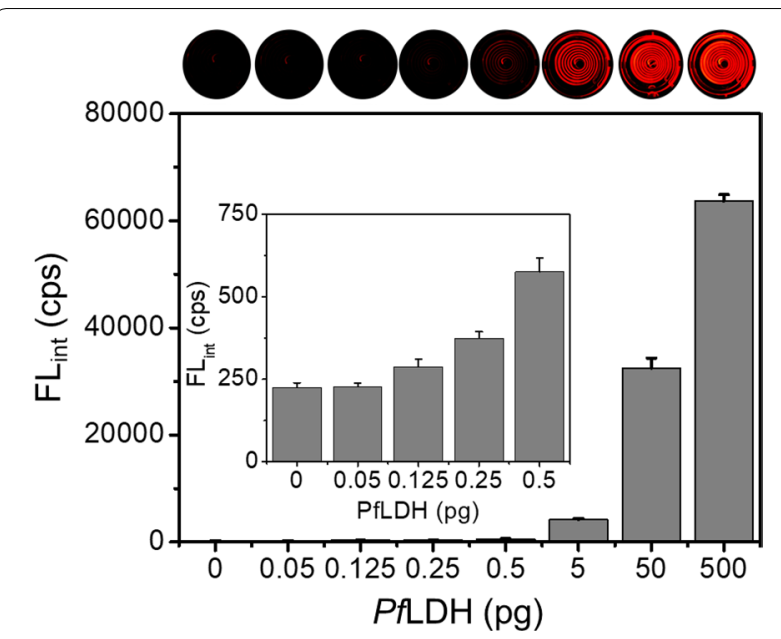

Fig. 4 Diagnosis of PfLDH using the microfluidic microplate-based immunoassay. Chemiluminescence intensity $(n=3)$ and chemiluminescence images of the microfluidic microplate to the detection of PfLDH

for the diagnosis and showing that high-sensitive diagnosis to the PfLDH. Based on the results, the microfluidic microplate-based immunoassay shows that it not only brings cost-effective for antibody use but also provides easier, simpler, faster, and superior sensitive diagnosis than recently developed sensors.

\section{Conclusions}

In conclusion, we demonstrated that simple, ultrafast, and accurate diagnosis of PfLDH using microfluidic microplates is possible. We reduced the amount of reagent required for diagnosis to $5 \mu \mathrm{L}$ and reduced the diagnosis time to $90 \mathrm{~min}$. The microfluidic microplatebased sensing platform provides a user-friendly method and a cost-effective approach for an immunoassay-based method for PfLDH diagnosis. Our sensing platform with optimized antibody pairs of capture and detection antibodies showed highly sensitive, selective, and specific diagnosis of PfLDH. We expect that microfluidic microplates will be used for malaria diagnosis rapidly and accurately in hospitals.

\section{Experimental section}

\subsection{Materials}

The microfluidic microplate plate (Optimiser ${ }^{\mathrm{TM}}$ microplate), holder, and absorbent pad were provided from MiCo BioMed Co., Ltd. (Seoul, Korea). Mouse monoclonal PfLDH antibody was purchased from Fapon Biotech (BRCMALS212, Guangdong, China), and rabbit polyclonal PfLDH antibody was purchased from LifeSpan BioScience, Inc. (LS-C488775, Seattle, USA). PfLDH and $P v \mathrm{LDH}$ were provided by BioNano Health Guard Research Center (H-GUARD). Polyclonal anti-rabbit HRP-tagged antibody (HRP-Ab) was obtained from Cell Signaling Technology, Inc. (Danvers, USA). Phosphatebuffered saline (PBS), blocking solution (StartingBlock ${ }^{\mathrm{TM}}$ ) and HRP substrate kit (QuantaRed ${ }^{\mathrm{TM}}$ Enhanced Chemifluorescent HRP substrate kit) were purchased from Thermo Fisher Scientific Ltd. (Waltham, USA). Bovine serum albumin (BSA) and sodium carbonate were purchased from Sigma-Aldrich (Louis, USA). Human serum (from human male AB plasma, USA origin, sterile-filtered) was purchased from Sigma-Aldrich (Louis, USA).

\subsection{Expression and purification of PfLDH}

As malaria biomarkers, $P f L D H$ and $P v \mathrm{LDH}$ were prepared for malaria diagnostics. In order to clone $P f L D H$ and $P v \mathrm{LDH}$, the full length gene encoding for the $\mathrm{LDH}$ was amplified via the polymerase chain reaction (PCR).
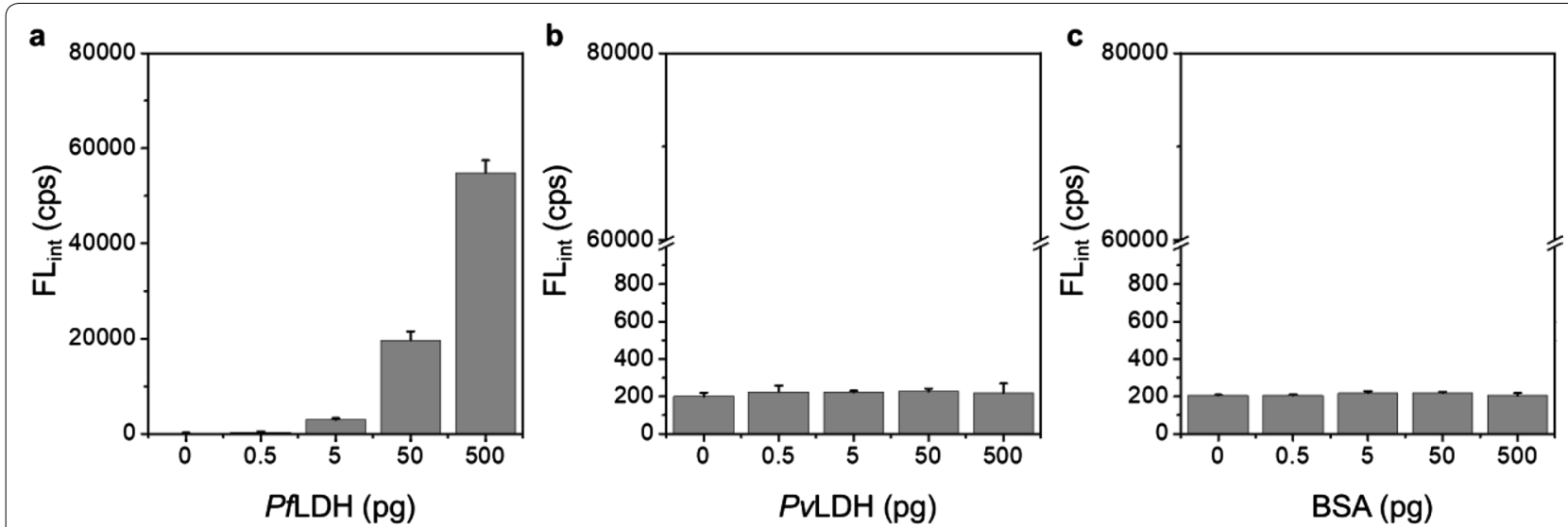

Fig. 5 Selectivity and specificity of microfluidic microplate-based immunoassay for detection of $P f L D H$. Diagnosis of $\mathbf{a} P f L D H, \mathbf{b} P V L D H$, and $\mathbf{c} B S A$ in PBS-based blocking solution $(n=3)$ 
a

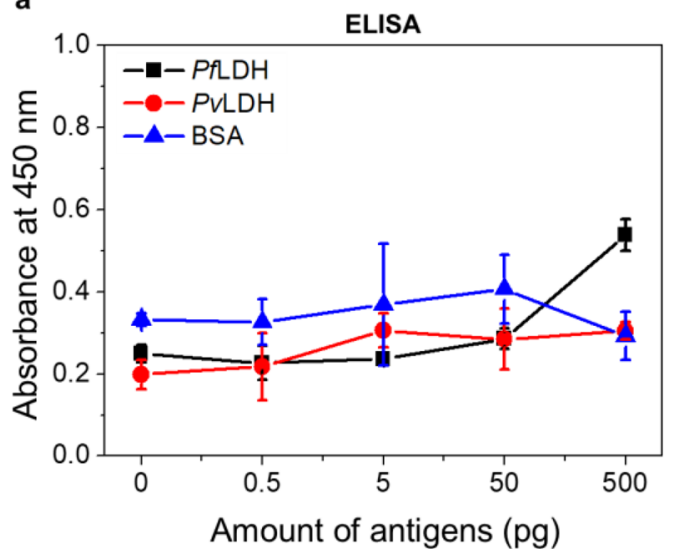

b

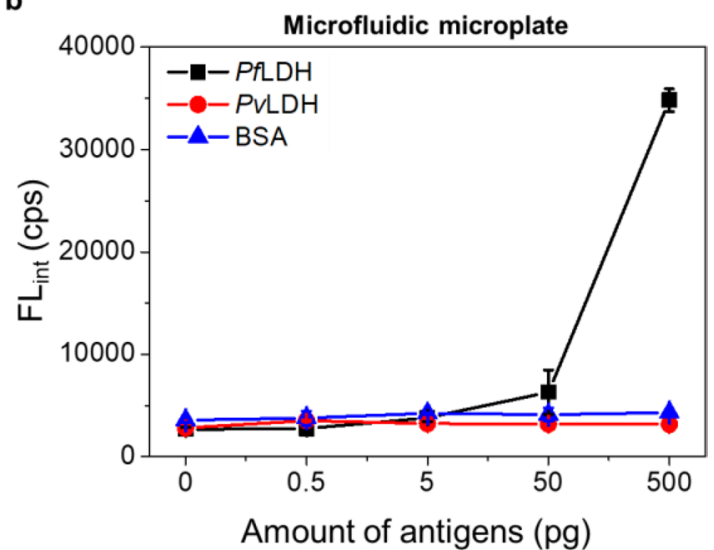

Fig. 6 Diagnosis of PfLDH, PVLDH, and BSA in human serum using a ELISA and $\mathbf{b}$ microfluidic microplate $(\mathrm{n}=3)$. All antigens were prepared in the range of $0-500 \mathrm{pg}$ in human serum

Table 1 Comparison of recent PfLDH detection studies

\begin{tabular}{|c|c|c|c|c|c|c|}
\hline Diagnosis & Target & Bio-recognition & Output & LOD & Volume & References \\
\hline Microfluidic microplate & PfLDH in buffer & Antibody & Fluorescence intensity & $0.025 \mathrm{pg} / \mu \mathrm{L}$ & $5 \mu \mathrm{L}$ & This study \\
\hline Microfluidic microplate & PfLDH in human serum & Antibody & Fluorescence intensity & $1 \mathrm{pg} / \mu \mathrm{L}$ & $5 \mu \mathrm{L}$ & This study \\
\hline ELISA & PfLDH in buffer & Antibody & Absorbance & $0.1 \mathrm{pg} / \mu \mathrm{L}$ & $100 \mu \mathrm{L}$ & This study \\
\hline Lateral flow immunoassay & PfLDH in buffer & Antibody & Colorimetric assay & $10 \mathrm{pg} / \mu \mathrm{L}$ & $30 \mu \mathrm{L}$ & {$[31]$} \\
\hline AuNPs based aptasensor & $\begin{array}{l}\text { PfLH in lysed RBCs }{ }^{\mathrm{a}} \\
\text { solution (Mimic real } \\
\text { sample) }\end{array}$ & Aptamer & Colorimetric assay & $38 \mathrm{pg} / \mu \mathrm{L}$ & $10 \mu \mathrm{L}$ & {$[32]$} \\
\hline MNP-Qdot aptasensor & PfLDH in buffer & Aptamer & Fluorescence intensity & $0.0066 \mathrm{pg} / \mu \mathrm{L}$ & $100 \mu \mathrm{L}$ & {$[33]$} \\
\hline $\begin{array}{l}\text { Aptamer-tethered enzyme capture } \\
\text { (APTEC) assay }\end{array}$ & PfLDH in buffer & Aptamer & Colorimetric assay & $4.9 \mathrm{pg} / \mu \mathrm{L}$ & $10 \mu \mathrm{L}$ & {$[34]$} \\
\hline $\begin{array}{l}\text { Aptamer-tethered enzyme capture } \\
\text { (APTEC) assay }\end{array}$ & PfLH in serum & Aptamer & Colorimetric assay & $50 \mathrm{pg} / \mu \mathrm{L}$ & $40 \mu \mathrm{L}$ & {$[35]$} \\
\hline
\end{tabular}

a $R B C$ red blood cells

The PCR product was inserted into the $\mathrm{pET} 21$ a vector using to generate $\mathrm{pET}-P f \mathrm{LDH}$ and $\mathrm{pET}-\mathrm{P} v \mathrm{LDH}$. The gene was all verified by DNA sequencing, and transformed into the expression host, E. coli BL21 (DE3) (Stratagene, CA) for the expression of the recombinant proteins. The transformed cells were grown at $37{ }^{\circ} \mathrm{C}$ with shaking to an OD600 of 0.6. The cells were induced with $1 \mathrm{mM}$ isopropyl-2-D-thiogalactopyranoside (IPTG, GibcoBRL, MD), and grown for an additional $14 \mathrm{~h}$ at $25^{\circ} \mathrm{C}$. The cells were then harvested and disrupted via sonication, after which the soluble and insoluble fractions were separated by centrifugation. The soluble fractions were loaded onto a IDAminiexcellose affinity column (Bioprogen Co., Republic of Korea) and washed three times with equilibration buffer (50 mM Tris-Cl, $0.5 \mathrm{~N} \mathrm{NaCl}, \mathrm{pH} 8.0$ ), respectively. The recombinant proteins were then eluted with $0.5 \mathrm{M}$ imidazole in the same buffer $(50 \mathrm{mM}$ Tris-Cl, $0.5 \mathrm{~N} \mathrm{NaCl}, \mathrm{pH}$ 8.0), and dialyzed against phosphate-buffered saline (PBS,
pH7.4). The purified $P f \mathrm{LDH}$ and $P v \mathrm{LDH}$ were resolved on $12 \%$ Sodium dodecyl sulfate-polyacrylamide gel electrophoresis (SDS-PAGE) and the gels were stained with Coomassie's Brilliant Blue R250. Protein concentrations were determined by the Bradford method, using bovine serum albumin as a standard.

\subsection{Validation of antibody pairs using ELISA}

To select the antibody pairs for detection of PfLDH, $\mathrm{Cap}-\mathrm{Ab}$ and 1 st-Ab were selected by ELISA. As a Cap$\mathrm{Ab}$, mouse monoclonal PfLDH antibody $(200 \mu \mathrm{L}, 2 \mu \mathrm{g} /$ $\mathrm{mL})$ dissolved in sodium bicarbonate $1 \mathrm{M}(\mathrm{pH}$ 9.6), is incubated in a 96-well plate (Corning ${ }^{\circledR} 96$ Well EIA/RIA Assay Microplate) at $4{ }^{\circ} \mathrm{C}$ for overnight. After the reaction, BSA $1 \%$ in PBS buffer $(100 \mu \mathrm{L})$ was added to the wells and reacted at $37{ }^{\circ} \mathrm{C}$ for $30 \mathrm{~min}$. After the removal of BSA solution, PfLDH (100 $\mu \mathrm{L}$ dissolved in PBS) was added to the wells in a concentration range of $1 \mu \mathrm{g} / \mathrm{mL}$ to 
$100 \mu \mathrm{g} / \mathrm{mL}$ and reacted at $37^{\circ} \mathrm{C}$ for $120 \mathrm{~min}$. After PfLDH treatment, rabbit polyclonal $P f \mathrm{LDH}$ antibody as a 1 st- $\mathrm{Ab}$ (100 $\mu \mathrm{L}, 1 / 2000$ dilution) was immediately added onto the PfLDH solution. After $120 \mathrm{~min}$ incubation at $37^{\circ} \mathrm{C}$, the wells were washed 2 times with PBS buffer. Then, $\mathrm{HRP}-\mathrm{Ab}$ was added on the wells and reacted at $37^{\circ} \mathrm{C}$ for $120 \mathrm{~min}$. Once again, the wells were washed 4 times with PBS buffer. Finally, TMB substrate reagent (BD Biosciences, USA) composed of TMB and hydrogen peroxide are mixed at a ratio of $1: 1$, and $100 \mu \mathrm{L}$ was added each well. After $5 \mathrm{~min}$, stop solution was added onto the wells and measured absorbance at $450 \mathrm{~nm}$ in microplate reader (Multiskan ${ }^{\text {TM }}$ FC Microplate Photometer, Thermo Fisher Scientific, USA).

\subsection{Immunoassay of PfLDH using the microfluidic microplate}

The immunoassay of PfLDH in the microfluidic microplate was performed in the same order as conventional ELISA. Cap-Ab $(5 \mu \mathrm{L}, 10 \mu \mathrm{g} / \mathrm{mL})$ dispersed in coating buffer (PBS and carbonate-bicarbonate buffer) was first immobilized on the microfluidic channel for $10 \mathrm{~min}$. Five microliters of blocking solution were added to the channels and incubated for $10 \mathrm{~min}$. Next, PfLDH (each $5 \mu \mathrm{L}, 0-100 \mathrm{ng} / \mathrm{mL})$ and $1 \mathrm{st}-\mathrm{Ab}(1 / 100$ dilution) were treated and incubated for $10 \mathrm{~min}$ in order. The microplates were then incubated with $5 \mu \mathrm{L}$ PBS for $10 \mathrm{~min}$ to remove unbound substances and were treated with HRP-tagged Ab (1/2500 dilution) for $10 \mathrm{~min}$. Then, all channels were washed with PBS $(30 \mu \mathrm{L})$ twice. After washing, Quantared ${ }^{\mathrm{TM}}$ Enhanced Chemifluorescent HRP Substrate (Enhancer solution: Stable peroxide solution: $\mathrm{ADHP}=50: 50: 1)$ was added to the channel for chemiluminescence. After $10 \mathrm{~min}$, the chemiluminescent signal was measured using a BioTek multimode reader (Cytation5, USA). Additionally, the chemiluminescence image was observed by stereomicroscope (SMZ18, Nikon, Japan) with a fluorescence filter (excitation $530 \mathrm{~nm}$ ). To confirm the diagnostic ability of $P f L D H$ in human serum, $P f L D H, P v L D H$ and BSA were prepared from human serum. Three antigens were prepared in PBS 10 times higher than the target concentration before diagnosis. These antigens were then spiked in human serum at a volume ratio of $1: 9$. The immunoassay procedure was the same as described above.

\footnotetext{
Abbreviations

WHO: World Health Organization; P. falciparum: Plasmodium falciparum; P. vivax: Plasmodium vivax; LDH: Lactate dehydrogenase; HRP2: Histidine rich protein2; PfLDH: Plasmodium falciparum lactate dehydrogenase; PVLDH: Plasmodium vivax lactate dehydrogenase; RDTs: Rapid diagnostic tests; ELISA: Enzyme-linked immunosorbent assay; TMB: 3,3',5,5'-tetramethylbenzidine; ADHD: 10-acetyl-3,7-dihydroxyphenoxazine; HRP: Horseradish peroxidase; Cap-Ab: Capture antibody; 1st-Ab: Primary antibody; HRP-Ab: HRP-tagged
}

antibody; PBS: Phosphate-buffered saline; BSA: Bovine serum albumin; LOD: Limit of detection; PCR: Polymerase chain reaction; SDS-PAGE: Sodium dodecyl sulfate-polyacrylamide gel electrophoresis; APTEC: Aptamer-tethered enzyme capture; H-GUARD: BioNano Health Guard Research Center.

\section{Acknowledgements}

This work was supported by the Basic Science Research Program through the National Research Foundation of Korea (NRF) funded by Ministry of Science and ICT (MSIT) (NRF-2019R1C1C1006084 and NRF-2019R1C1C1006867), The Center for BioNano Health-Guard funded by the Ministry of Science and ICT as Global Frontier Project (H-GUARD_2013M3A6B2078950) and KRIBB Research Initiative Program.

\section{Authors' contributions}

WSL takes the lead through the whole experiments. WSL and KJK performed the detection of PfLDH by using microfluidic microplate. KP, SYL, UJL, and YBS performed the ELISA for selection of antibody pairs and prepared malaria biomarkers (PfLDH and PVLDH). JJ conceived of the idea and supervised the project. WSL, TK and JJ mainly wrote the manuscript and all authors provided feedback and helped the completion of the final manuscript. All authors read and approved the final manuscript.

\section{Funding}

This work was supported by the Basic Science Research Program through the National Research Foundation of Korea (NRF) funded by Ministry of Science and ICT (MSIT) (NRF-2019R1C1C1006084 and NRF-2019R1C1C1006867), The Center for BioNano Health-Guard funded by the Ministry of Science and ICT as Global Frontier Project (H-GUARD_2013M3A6B2078950) and KRIBB Research Initiative Program.

\section{Availability of data and materials}

All data generated or analyzed during this study are included in this published article.

\section{Competing interests}

The authors declare that they have no competing interests.

\section{Author details}

${ }^{1}$ Environmental Disease Research Center, Korea Research Institute of Bioscience and Biotechnology (KRIBB), 125 Gwahak-ro, Yuseong-gu, Daejeon 34141, Republic of Korea. ${ }^{2}$ Department of Nanobiotechnology, KRIBB School of Biotechnology, University of Science and Technology (UST), 217 Gajeong-ro, Yuseong-gu, Daejeon 34113, Republic of Korea. ${ }^{3}$ Bionanotechnology Research Center, Korea Research Institute of Bioscience and Biotechnology (KRIBB), 125 Gwahak-ro, Yuseong-gu, Daejeon 34141, Republic of Korea. ${ }^{4}$ Dept. of General Education, Daejeon Health Institute of Technology, 21 Chungjeon-ro, Dong-gu, Daejeon 34504, Republic of Korea. ${ }^{5}$ BioNano Health Guard Research Center, 125 Gwahak-ro, Yuseong-gu, Daejeon 34141, Republic of Korea. ${ }^{6}$ Department of Biochemistry, College of Natural Sciences, Chungnam National University, 99 Daehak-ro, Yuseong-gu, Daejeon 34134, Republic of Korea.

Received: 17 October 2019 Accepted: 31 March 2020 Published online: 11 April 2020

\section{References}

1. M.A. Phillips, J.N. Burrows, C. Manyando, R.H. Van Huijsduinen, W.C. Van Voorhis, T.N.C.C. Wells, Nat. Rev. Dis. Prim. 3, 17 (2017)

2. WHO, World Malaria Report 2018 (World Health Organization, Geneva, 2018)

3. World Health Organization, World Malaria Report 2018 (World Health Organization, Geneva, 2015)

4. R.W. Snow, BMC Med. 13, 14 (2015)

5. K.V. Ragavan, S. Kumar, S. Swaraj, S. Neethirajan, Biosens. Bioelectron. 105, 188 (2018)

6. Y.W. Cheung, R.M. Dirkzwager, W.C. Wong, J. Cardoso, J.D.N. Costa, J.A. Tanner, Biochimie 145, 131 (2018)

7. A. Molina-Cruz, M.M. Zilversmit, D.E. Neafsey, D.L. Hartl, C. Barillas-Mury, Annu. Rev. Genet. 50, 447 (2016) 
8. P. Li, H. Xing, Z. Zhao, Z. Yang, Y. Cao, W. Li, G. Yan, J. Sattabongkot, L. Cui, Q. Fan, Acta Trop. 152, 26 (2015)

9. C.M. Solano, S.A. Okoth, J.F. Abdallah, Z. Pava, E. Dorado, S. Incardona, C.S. Huber, A.M. Oliveira, D. Bell, V. Udhayakumar, J.W. Barnwell, PLoS One 10, e0131576 (2015)

10. P.K. Bharti, H.S. Chandel, A. Ahmad, S. Krishna, V. Udhayakumar, N. Singh, PLOS ONE 11, 1 (2016)

11. G.M.R. Viana, S.A. Okoth, L.S. Flannery, D.R.L. Barbosa, A.M. de Oliveira, I.F. Goldman, L.C. Morton, C. Huber, A. Anez, R.L.D. Machado, L.M.A. Camargo, S.C.N. Do Valle, M.M. Povoa, V. Udhayakumar, J.W. Barnwell, PLoS One 12, 1 (2017)

12. K.B. Beshir, N. Sepúlveda, J. Bharmal, A. Robinson, J. Mwanguzi, A.O. Busula, J.G. De Boer, C. Sutherland, J. Cunningham, H. Hopkins, Sci. Rep. 7, 1 (2017)

13. Y.-W. Cheung, J. Kwok, A.W.L. Law, R.M. Watt, M. Kotaka, J.A. Tanner, Proc. Natl. Acad. Sci. 110, 15967 (2013)

14. C.F. Markwalter, K.M. Davis, D.W. Wright, Anal. Biochem. 493, 30 (2016)

15. F.E. McKenzie, J. Sirichaisinthop, R.S. Miller, R.A. Gasser, C. Wongsrichanalai, Am. J. Trop. Med. Hyg. 69, 372 (2003)

16. C. Wongsrichanalai, M.J. Barcus, S. Muth, A. Sutamihardja, W.H. Wernsdorfer, Am. J. Trop. Med. Hyg. 77, 119 (2007)

17. A.H.D. Kilian, W.G. Metzger, E.J. Mutschelknauss, G. Kabagambe, P. Langi, R. Korte, F. Von Sonnenburg, Trop. Med. Int. Heal. 5, 3 (2000)

18. P. Gillet, J. Maltha, V. Hermans, R. Ravinetto, C. Bruggeman, J. Jacobs, Malar. J. 10, 1 (2011)

19. C.K. Murray, R.A. Gasser, A.J. Magill, R.S. Miller, Clin. Microbiol. Rev. 21, 97 (2008)

20. C. Kim, G. Hoffmann, P.C. Searson, ACS Sensors 2, 766 (2017)

21. D. Bell, C. Wongsrichanalai, J.W. Barnwell, Nat. Rev. Microbiol. 4, 682 (2006)
22. D. Bell, R.W. Peeling, Nat. Rev. Microbiol. 4, S34 (2006)

23. C.F. Markwalter, K.M. Ricks, A.L. Bitting, L. Mudenda, D.W. Wright, Talanta 161, $443(2016)$

24. J. Kai, A. Puntambekar, N. Santiago, S.H. Lee, D.W. Sehy, V. Moore, J. Han, C.H. Ahn, Lab Chip 12, 4257 (2012)

25. S.K. Vashist, P.B. Luppa, L.Y. Yeo, A. Ozcan, J.H.T. Luong, Trends Biotechnol. 33, 692 (2015)

26. W. Jung, J. Han, J.W. Choi, C.H. Ahn, Microelectron. Eng. 132, 46 (2014)

27. J.M. Lü, P.H. Lin, Q. Yao, C. Chen, J. Cell Mol. Med. 14, 840 (2010)

28. E. Güven, K. Duus, M.C. Lydolph, C.S. Jørgensen, I. Laursen, G. Houen, J. Immunol. Methods 403, 26 (2014)

29. S.K. Martin, G.H. Rajasekariah, G. Awinda, J. Waitumbi, C. Kifude, Am. J. Trop. Med. Hyg. 80, 516 (2009)

30. M. Tonigold, J. Simon, D. Estupiñán, M. Kokkinopoulou, J. Reinholz, U. Kintzel, A. Kaltbeitzel, P. Renz, M.P. Domogalla, K. Steinbrink, I. Lieberwirth, D. Crespy, K. Landfester, V. Mailänder, Nat. Nanotechnol. 13, 862 (2018)

31. C.L. Mthembu, M.I. Sabela, M. Mlambo, L.M. Madikizela, S. Kanchi, H. Gumede, P.S. Mdluli, Anal. Methods 9, 5943 (2017)

32. P. Jain, B. Chakma, N.K. Singh, S. Patra, P. Goswami, Mol. Biotechnol. 58 497 (2016)

33. C. Kim, P.C. Searson, Bioconjug. Chem. 28, 2230 (2017)

34. R.M. Dirkzwager, A.B. Kinghorn, J.S. Richards, J.A. Tanner, Chem. Commun. $\mathbf{5 1 , 4 6 9 7 ( 2 0 1 5 )}$

35. R.M. Dirkzwager, S. Liang, J.A. Tanner, ACS Sensors 1, 420 (2016)

\section{Publisher's Note}

Springer Nature remains neutral with regard to jurisdictional claims in published maps and institutional affiliations.

\section{Submit your manuscript to a SpringerOpen ${ }^{\circ}$ journal and benefit from:}

- Convenient online submission

- Rigorous peer review

- Open access: articles freely available online

- High visibility within the field

- Retaining the copyright to your article

Submit your next manuscript at $\boldsymbol{\nabla}$ springeropen.com 